\title{
Design and Implementation of a Fingerprint Lock System
}

\author{
${ }^{1}$ Amuda F.A ${ }^{2}$ Tennyson D.I \\ 1,2 Electrical Engineering Department Hussaini Adamu Federal Polytechnic, Kazaure Jigawa State, Nigeria.
}

\begin{abstract}
The use of fingerprint for identification has been employed in law enforcement for about a century. A fingerprint locker system using microcontroller uses fingerprint recognition system as a process of verifying the fingerprint image to open the electronic lock. This research highlights the development of fingerprint verification system using Arduino 1.6.3. Verification is completed by comparing the data of authorized fingerprint image with incoming fingerprint image. The incoming fingerprint image will first go through the extraction and filtering processes through which the information about it is obtained. Then the information of incoming fingerprint image will undergo the comparison process to compare it with authorized fingerprint image. In this work, the fingerprint module was trained to learn and identify whether the incoming fingerprint image is genuine or forgery. A much broader application of fingerprint is for personal authentication, for instance to access a computer, a network, an ATM-machine, a car or a home.
\end{abstract}

\subsection{INTRODUCTION}

In spite of numerous advantages of biometrics-based personal authentication systems over traditional security systems based on token or knowledge, they are vulnerable to attacks that can decrease their security considerably. Biometrics-based personal authentication system that use physiological (fingerprint, face) or behavioral (speech, handwriting) traits are becoming increasingly popular, compared to traditional systems that are based on tokens (key) or knowledge (password).Fingerprint-based identification is one of the most important biometric technologies which have drawn a substantial amount of attention recently. Fingerprint technology is so common in personal identification that it has been well established. Each human has unique owns fingerprint, even the twin have different fingerprint. So fingerprint recognition is useful in security law application. The electronic lock using fingerprint recognition involves a process of verifying the user's identity by using fingerprint recognition as a key to the electronic lock. This work highlights the development of fingerprint recognition system using ARDUINO 1.6.3. to recognize the input fingerprint image from the stored samples in bmp, tif; tiff; jpg; jpeg; gif file type. Then the information of the recognized fingerprint image will be store in database for verification authorized user. These fingerprint recognition systems are based on the hypothesis that the human fingerprint is unique. It is important to validate the individuality of fingerprint in order to use the fingerprint image for security related system. In real application, the fingerprint data is recorded by using USB fingerprint scanner and then sent to a recognizer that will check the similarity of the user's fingerprint.

\subsection{DESIGN AND IMPLEMENTATION}

The design and implementation of each of the fundamental circuit units and how the program was implemented to control the design and perform the required functionality is hereby presented.

\subsection{POWER SUPPLY}

This unit comprises of the transformer, diode rectifier, filtering capacitor, switching relay, back-up battery and regulators.

\subsection{Transformer}

The local main is expected to deliver $240 \mathrm{~V}$, the system voltage requirement is $12 \mathrm{~V}$ and $5 \mathrm{~V}$, therefore a $240 \mathrm{~V} / 15 \mathrm{~V}$ transformer was used. The system input resistance is about $200 \Omega$, therefore the expected load current is

$$
\mathrm{I}=\mathrm{V} / \mathrm{R}=5 / 200=250 \mathrm{~mA}
$$

A transformer with the current rating of $500 \mathrm{~mA}$ which is greater than load current was used. Thus the power rating of the transformer was completed to be

$$
\mathrm{S}=\mathrm{VI}=12 \times 500 \mathrm{~mA}=6 \mathrm{VA}
$$

\subsection{Rectifier}

The voltage employed is bridge rectifier arrangement. The circuit diagram is as shown In fig. 1 below 


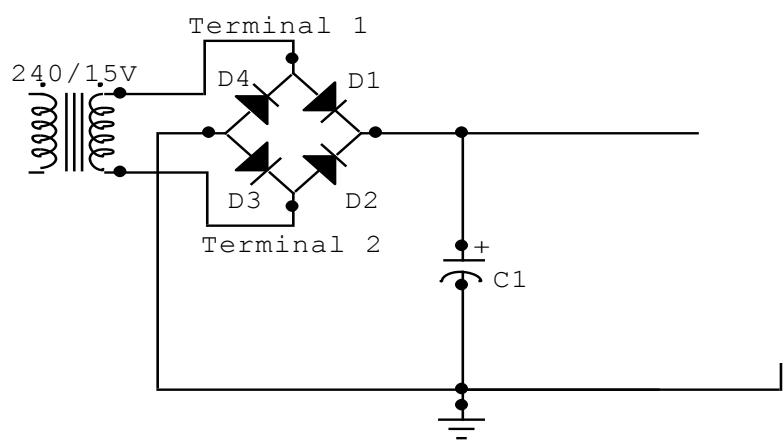

2.4 The filter.

Fig.1: Full-wave Bridge Rectifier

This is made up of capacitor connected across the out put of the rectifier to smoothen the voltage to have the minimum ripple factor (at least $10 \%$ of the dc voltage). It is preferable to choose a filtering capacitor that will hold the peak-to-peak ripples at approximately $10 \%$ of the peak voltage. Therefore;

$\mathrm{V}_{\text {ripple }}=0.1 \mathrm{~V}_{\text {peak }}$

$\mathrm{V}_{\text {ripple }}=0.1 \times 16.97$

$\mathrm{V}_{\text {ripple }}=1.697 \mathrm{~V}$

But also $\mathrm{V}_{\text {ripple }}=\mathrm{I} / 2 \mathrm{fC}$ for full wave

Where; $\mathrm{I}=$ current taken by the load

$\mathrm{f}=$ frequency of supply

$\mathrm{C}=$ filtering capacitor

$\mathrm{C}=\mathrm{I} / 2 \mathrm{fV}_{\text {ripple }}$

$=0.17 /(2 \times 50 \times 1.697)$

$\mathrm{C}=1001.7 \mu \mathrm{F}$

From this calculation, a standard capacitor of $2200 \mu \mathrm{F}$ was chosen.

2.5 The Regulator.

The regulator is a single chip that regulates the ripple free rectified voltage to give a constant out put voltage. Since the circuit needs a supply voltage of $12 \mathrm{~V}$ and $5 \mathrm{~V}$, a $12 \mathrm{~V}$ and $5 \mathrm{~V}$ regulators were used. The percentage regulation or simply regulator of a power supply is given by:

$\%$ regulation $=\left[\left(\mathrm{V}_{\max }-\mathrm{V}_{\min }\right) / \mathrm{V}_{\max }\right] \times 100$

Where;

$\mathrm{V}_{\max }=$ maximum dc output voltage

$\mathrm{V}_{\min }=$ minimum dc output voltage

In a general form

$\%$ regulation $=\left[\left(\mathrm{V}_{\text {no load }}-\mathrm{V}_{\text {full load }}\right) / \mathrm{V}_{\text {full load }}\right] \times 100$

The power supply, sensory, controller and the microcontroller units are connected as shown in Fig, 2 to form the lock system, 


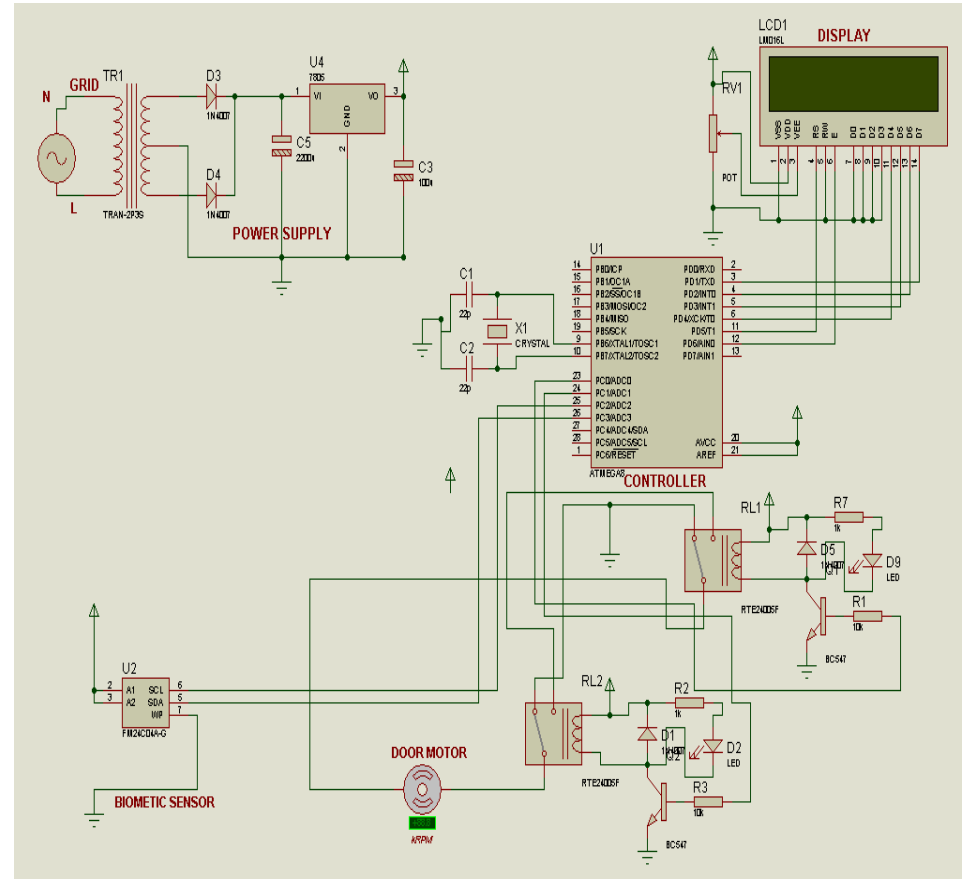

FIG.2 CIRCUIT DIAGRAM OF THE SYSTEM

\subsection{LOADING THE PROGRAM}

The program developed and loaded on the microcontroller by means of an interfacer known as the programmer. The program and Hex code is given in appendix.

\subsection{Assembler}

The assembler used for this project is the MPLAB version 5.7 which was downloaded from the microchip website. This is windows based integrated development environment (IDE) software which gives support for the PIC and other microcontrollers. This software contains a full featured editor, three operating modes (editor, emulator, simulator, a project manager, customizable tool bar and key mapping, status bar with project information.

Arduino 1.6.3 allows one to edit source files (either in assembly or ' $\mathrm{C}$ '). Other features include debugging using:

- Source files

- Absolute listing file

\subsection{ARDUINO Programmer}

This was used to burn the hex files into the microcontroller. This programmer has the facility to program a ATMEGA328, erase the EEPROM, and also verify the already written program for errors.

\subsection{PROGRAM FLOW CHART}

The program flow chart is given in Fig. 3. 


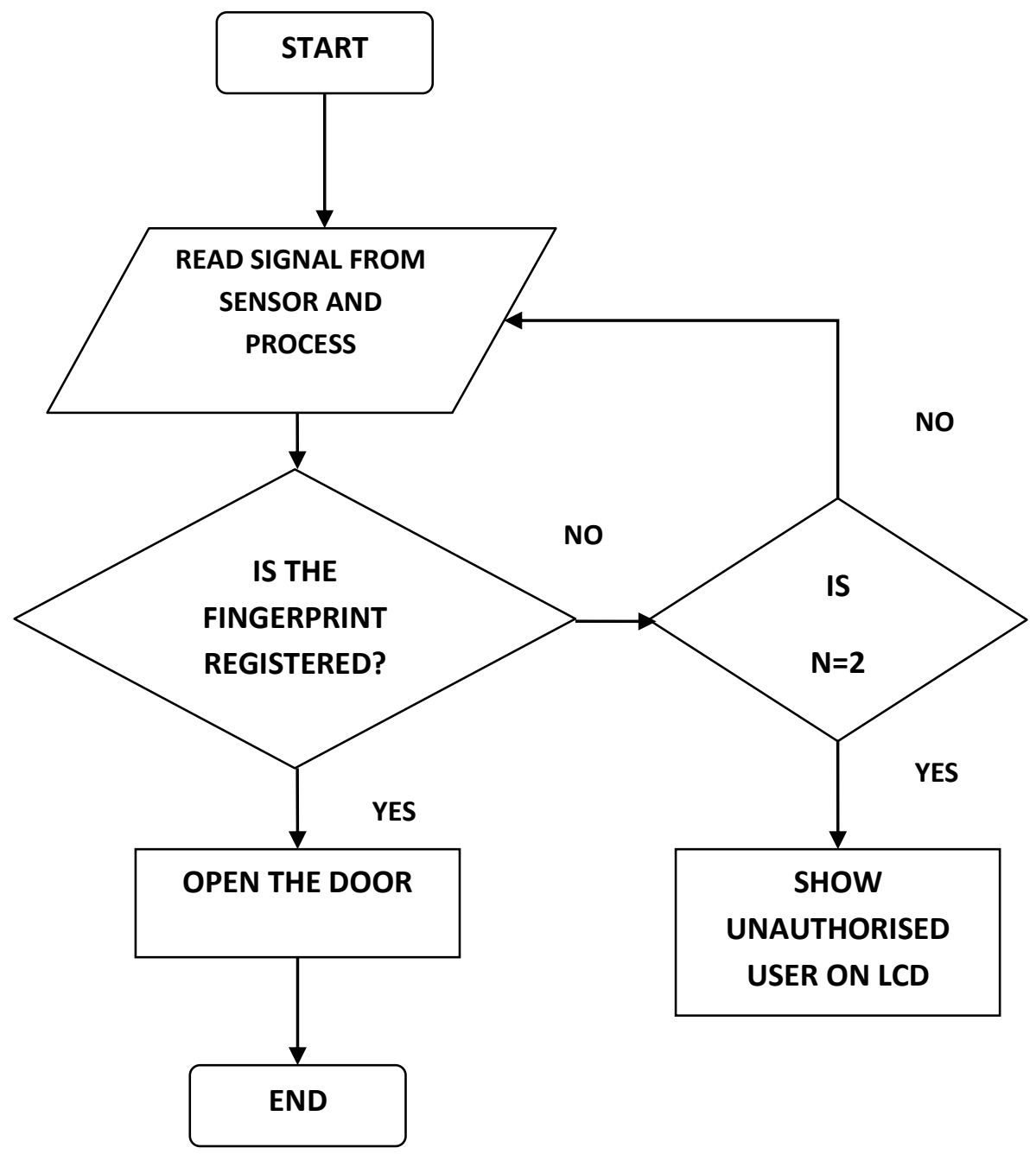

Fig. 3: The program flow chart

3.4 Design of switching unit

The current reaching the base of the transistor is $0.43 \mathrm{~mA}$

$$
\begin{gathered}
R=\frac{V}{I} \\
=\frac{4.9}{0.43 m A} \\
=11 K
\end{gathered}
$$

Therefore $10 \mathrm{~K}$ was selected as the suitable resistor

$$
\begin{gathered}
I_{B}=\frac{V_{B B}-V_{B E}}{R_{B}} \\
=\frac{4.9-0.7}{10 \mathrm{~K}} \\
=0.42 \mathrm{~mA} \\
I_{C}=\beta I_{B} \\
=150 \times 0.42 \mathrm{~mA} \\
=63 \mathrm{~mA} \\
I_{C} \approx I_{E}=63 \mathrm{~mA}
\end{gathered}
$$

3.5 Current drawn by motor at full load

The current drawn by the motor at full load when it's rotating clockwise 
Where $I_{a}$, is the armature current $=10 \mathrm{~mA}$

$$
I_{T}=I_{C}+I_{a}+I_{f}
$$

And $I_{f}$ is the field current $=0.4 \mathrm{~mA}$

$$
\begin{gathered}
I_{T}=63 m A+10 m A+0.4 m A \\
=73 m A
\end{gathered}
$$

Also driving current during anticlockwise motion of motor $=73 \mathrm{~mA}$

\subsection{Power of motor}

Power of motor at full load, $P_{M=} V_{d c} \times I_{T}$

$$
\begin{gathered}
=4.9 \times 73.4 \mathrm{~mA} \\
=359.66 \mathrm{~mW}
\end{gathered}
$$

\subsection{Speed of motor}

Input voltage, $V=4.9 \mathrm{~V}$

$$
N=\frac{9.55 \times E \times I}{T}
$$

Rated max \%torque, $T=50 \%$

\subsection{Power consumed by LEDs}

$$
\begin{gathered}
N=\frac{9.55 \times 4.9 \times 73 \mathrm{~mA}}{0.5} \\
=6.8 \mathrm{rps} \\
=408 \mathrm{rpm}
\end{gathered}
$$

For red LED we decide to use resistor $\mathrm{R}=100 \Omega$ and $\mathrm{V}=4.9 \mathrm{~V}$

$$
\begin{gathered}
\frac{1}{R_{T}}=\frac{1}{100}+\frac{1}{1 K} \\
\frac{1}{R_{T}}=\frac{11}{1000} \\
R_{T}=91 \Omega \\
I_{X}=\frac{91}{100+91} \times 15 \mathrm{~mA} \\
=7.1 \mathrm{~mA}
\end{gathered}
$$

The same current flow into the green LED

$$
\begin{gathered}
P_{L E D}=4 \times 7.1 \mathrm{~mA} \\
=34.79 \mathrm{~mA}
\end{gathered}
$$




\subsection{TESTS, RESULTS AND DISCUSSION}

This section deals with the description of tests performed on the various sections of the overall system and their corresponding results as well as the result of the overall system. In order to verify the correct functionality of the system, each component had to be tested individually. To achieve the effective testing of these various components, the following tools were used:

- Digital multimeter

- Bread board

- Logic probe

- Light emitting diodes

- Arduino 1.6.3. software

The testing was done on each and every components/sections that make up the circuit to ensure proper and satisfactory operation of the fingerprint lock. The debugging was done using the Arduino 1.6.3; Each and every section of the code was debugged properly to ensure proper functionality thus a step debugging was done. This is a facility in the software that enables you step into program and at the same time views the registers and flag settings.

\subsection{OVERALL SYSTEM}

The whole system was tested with various trials of fingers and only the registered fingers turned on the output DC motor to unlock the door as required. The relay 2 is used to turn on the DC motor in reverse mode to lock the door as required.

\subsection{POWER SUPPLY} conditions.

The power supply unit of $+5 \mathrm{~V}$ and $+12 \mathrm{~V}$ were tested for the output voltage under no-load and full-load

Under no-load, the voltage of the $+5 \mathrm{~V}$ supply section was measured to be $4.95 \mathrm{~V}$ while that of the $+12 \mathrm{~V}$ supply was measured to be $11.94 \mathrm{~V}$. At full-load, the respective voltages were measured as $4.85 \mathrm{~V}$ and $11.83 \mathrm{~V}$.

Voltage Regulation (V.R) is given as;

$$
V \cdot R=\frac{V_{N L}-V_{F L}}{V_{N L}} \times 100 \%
$$

Where,

$$
\begin{aligned}
& V_{N L}=\text { No-load Voltage } \\
& V_{F L}=\text { Full-load Voltage }
\end{aligned}
$$

For the units operating on $+5 \mathrm{~V}$,

$$
V \cdot R=\frac{4.95-4.85}{4.95} \times 100 \%=2.02 \%
$$

For the units operating on $+12 \mathrm{~V}$,

$$
V . R=\frac{11.89-11.41}{11.89} \times 100 \%=4.03 \%
$$

From the results obtained above, the performance of the power supply is satisfactory.

\subsection{CONCLUSION}

The aim of the work is to design a fingerprint lock system that can be used to lock and unlock a door system but its use can be extended to other electronic locking systems such as vaults. Having realized the device and found it working properly according to its design specifications and couple with the facts that relatively cheap components were involved in its realization, the aim of the research can be said to be achieved. The system can be used as an effective security lock.

\section{REFERENCES}

[1] Boylestad, R.L and Nashelsky, L. (1996). Electronic Devices and Circuit Theory, Prentice Hall, London.

[2] Forrest M. M. III (1984). Getting started in Electronics, Printed in the United States.

[3] Green, D. C. (1982). Digital Electronics Technology, Pitman Publishing Ltd. New Zealand.

[4] Theraja B.L. \& Theraja A.K. (2002). A textbook of Electrical Technology, S. Chand and Company Ltd. New Delhi. 
[5] Pavithra B.C, Myna B.C and Kavyashreem (2014) Fingerprint Based Bank Locker System Using Microcontroller. Proceedings of IRF International Conference, Pondicherry.

[6] Aditya A .S, Sastry P.R.K, Vislinu A.I.R, Vansiadhav, A. (2015). Fingerprint Based Door Locking System. International Journal of Engineering and Computer Science. Vol 4.

[7] Kawser W.N, Tonny S.K, and Sayed A. H.(2012) An Advanced Door Lock Security System Using palmtop Recognition System. International Journal of Computer Applications. Vol.56 No17.

[8] Hussaini H, Adamu M.Z., Adagun A.S., Ijemaru K, Dresanya B.O. (2014). Design of a GSM-Based Design of a GSM-Based Biometric Access Control System. Control Theory and Informatics. Vol.14. No8. 